\title{
Análise dialélica como ferramenta na seleção de genitores em feijão ${ }^{1}$
}

\author{
Diallel analysis as a tool when selecting parents for beans
}

\author{
Fabiani da Rocha ${ }^{2}$, Jussara Cristina Stinghen ${ }^{3}$, Murielli Sabrina Gemeli ${ }^{3}$ Jefferson Luís Mirelles Coimbra ${ }^{3 *}$ e \\ Altamir Frederico Guidolin ${ }^{3}$
}

\begin{abstract}
RESUMO - O sucesso de um programa de melhoramento de plantas autógamas depende da escolha de genitores capazes de produzir progênies com as características desejadas. Sendo assim, este estudo teve como objetivo determinar os valores das capacidades geral e específica de combinação de quatro genótipos de feijão para os caracteres estatura de planta (EP) em centímetros, altura de inserção do primeiro legume (IPL) em centímetros, diâmetro do colo (DC) em milímetros, número de legumes por planta (NLP) e número de grãos por legume (NGL), a fim de avaliar o potencial destes como genitores para uso em programas de melhoramento. Quatro genitores de feijão (BAF07, BAF09 e IPR Uirapuru do grupo comercial preto e BAF50 do grupo comercial carioca) foram hibridados em um dialelo completo para a obtenção dos híbridos $\mathrm{F}_{1}$ e recíprocos. $\mathrm{O}$ desempenho dos genitores, híbridos $\mathrm{F}_{1}$ e recíprocos foi avaliado a campo em um experimento em blocos casualizados, com duas repetições, durante a safra agrícola de 2009/10. Para análise dialélica foi utilizada a metodologia proposta por Griffing (1956), método I, onde são incluídas $\mathrm{n}^{2}$ combinações. O genótipo BAF07 pode ser empregado em blocos de cruzamentos quando o escopo do programa for aumentar os valores para EP, IPL, DC e NGL; foi possível observar ainda, através da magnitude dos componentes quadráticos a maior importância da capacidade geral de combinação, ou seja, dos efeitos aditivos no controle genético de características de importância agronômica em feijão.
\end{abstract}

Palavras-chave: Phaseolus vulgaris L.. Capacidade de combinação. Melhoramento genético.

\begin{abstract}
The success of a breeding programme for autogamous plants depends on the choice of parents capable of producing progeny with the desired characteristics. Therefore, the objective of this study was to determine the values of the general and specific combining capabilities of four bean genotypes, for the characteristics: plant height $(\mathrm{PH})$ in $\mathrm{cm}$; height of insertion of the first pod (HIP) in cm; stem diameter (SD) in mm; number of pods per plant (NPP); and number of grains per pod (NGP); in order to assess their potential for use as parents in breeding programmes. Four bean parents (BAF07, BAF09 and IPR Uirapuru of the black commercial group and BAF50 of the carioca commercial group) were hybridized employing a complete diallel in order to obtain the $F_{1}$ hybrids and their reciprocals. The performance of the parents, $F_{1}$ hybrids and reciprocals was evaluated in the field in an experimental design of randomised blocks with two replications, during the 2009/10 crop season. For diallel analysis the methodology proposed by Griffing (1956) was used: Method I, where $\mathrm{n}^{2}$ combinations are included. The BAF07 genotype can be used in blocks of crossings when the aim of the programme is to increase the values for PH, HIP, SD and NGP; it was also possible to observe a greater importance of the general combining capacity, by means of the magnitude of the quadratic components, i.e. of the additive effects in the genetic control of characteristics of agronomic importance in the bean.
\end{abstract}

Key words: Phaseolus vulgaris L.. Combining ability. Genetic Improvement.

\footnotetext{
*Autor para correspondência

'Recebido para publicação em 09/11/2011; aprovado em 13/09/2013

Pesquisa financiada pela UDESC, CNPq, CAPES e FAPESC

${ }^{2}$ Departamento de Genética, Escola Superior de Agricultura"Luiz de Queiroz”, Universidade de São Paulo, Piracicaba-SP, Brasil, fabiani. rocha@gmail.com

${ }^{3}$ Instituto de Melhoramento e Genética Molecular, Centro de Ciências Agroveterinárias, Universidade do Estado de Santa Catarina, Av. Luiz de Camões 2090, Conta Dinheiro, Lages-SC, Brasil, 88.520-000, jujustinghen@gmail.com, murigemeli@gmail.com, coimbrajefferson@udesc.br, a2afg@cav.udesc.br
} 


\section{INTRODUÇÃO}

O feijão (Phaseolus vulgaris L.) é um importante alimento, fornecendo proteína, vitaminas e minerais à população de uma forma barata (MIKLAS et al., 2006). Para que este grão continue disponível tanto para os produtores como para os consumidores, torna-se necessário que novas variedades sejam lançadas, visando atender a necessidade de ambos.

A variabilidade genética é de fundamental interesse para o melhorista, pois sem ela não há progresso no melhoramento de plantas. É ela que viabiliza o emprego de técnicas que possibilitam a identificação de genótipos superiores. A hibridação é uma das maneiras mais eficientes de explorar a variabilidade genética existente em muitas espécies (NASCIMENTO et al., 2004). Na condução de um programa de melhoramento por hibridação, um dos pontos mais importantes é estabelecer quais genitores deverão ser cruzados, já que o número de linhagens disponíveis para realização dos cruzamentos é muito grande, especialmente quando se pretende obter populações segregantes úteis, de onde seja possível extrair linhagens mais produtivas a partir do cruzamento entre genótipos endogâmicos melhorados, que, consequentemente, possuem altos níveis de produtividade (PEREIRA et al., 2007).

O sucesso de um programa de melhoramento de plantas autógamas depende da escolha de genitores capazes de gerar progênies com as características desejadas. A seleção de linhagens com desempenho superior se dá a partir de populações segregantes promissoras (ALGHAMDI, 2007). O uso de procedimentos que permitam a seleção dos melhores pais para os cruzamentos representa uma excelente ferramenta para a obtenção de populações elite, alvo de seleção (VALÉRIO et al., 2009).

No entanto, a escolha de genitores apenas com base em caracteres desejáveis é insuficiente para assegurar a obtenção de progênies com alto potencial genético. É fundamental avaliar o comportamento de variedades "per se" em híbridos, de forma que os genótipos utilizados nos cruzamentos tenham alta capacidade combinatória, para que assim produzam recombinações favoráveis em alta frequência (CARVAJAL et al., 1997; NASS, 1979).

Uma das formas de se determinar o potencial genético das variedades é a avaliação destas em cruzamentos entre si (FERREIRA; MOREIRA; HIDALGO, 2009). O exame da capacidade geral de combinação (CGC) de cada genitor auxilia no desenvolvimento de genótipos superiores, enquanto capacidade específica de combinação (CEC) estima a performance de híbridos (CRUZ; REGAZZI,
2004). Logo, a análise baseada na obtenção de progênies oriundas de diversos genitores é essencial para a formulação de estratégias eficientes para o melhoramento de variedades.

Sendo assim, este estudo teve como objetivo determinar os valores das capacidades geral e específica de combinação para os caracteres estatura de plantas, altura de inserção do primeiro legume, diâmetro do colo, número de legumes por planta e número de grãos por legume, para quatro genótipos de feijão, com foco na seleção de genitores.

\section{MATERIAL E MÉTODOS}

Quatro genitores de feijão (BAF07, BAF09 e IPR Uirapuru do grupo comercial preto e BAF50 do grupo comercial carioca) foram hibridados em um dialelo completo para a obtenção dos híbridos $\mathrm{F}_{1}$ e recíprocos. Os cruzamentos foram efetuados segundo a metodologia de Vieira (1967), com a emasculação do botão floral. O ensaio foi conduzido em casa de vegetação, durante o ano de 2009, em vasos de $10 \mathrm{~kg}$, com uma planta. A semeadura foi realizada em quatro épocas para garantia na coincidência da floração.

$\mathrm{O}$ desempenho dos genitores, híbridos $\mathrm{F}_{1}$ e recíprocos foi avaliado a campo, em um delineamento de blocos casualizados com duas repetições, durante a safra agrícola 2009/10. As unidades experimentais foram compostas de três linhas de um metro de comprimento, espaçadas em $0,5 \mathrm{~m}$. Para a avaliação foi considerada apenas a linha central da parcela, composta por 12 plantas, as quais foram individualmente avaliadas. Previamente à semeadura foi feita a adubação com NPK (Nitrogênio, Fósforo e Potássio), conforme a necessidade do solo e da cultura (REDE OFICIAL DE LABORATÓRIOS DE ANÁLISE DE SOLO E DE TECIDO VEGETAL, 2004). A aplicação de nitrogênio em cobertura foi efetuada quando as plantas atingiram o estádio de 3-4 folhas, com $50 \mathrm{~kg} \mathrm{ha}^{-1}$, na formulação da ureia. $\mathrm{O}$ controle de plantas invasoras foi feito com capina manual, de acordo com a necessidade.

Por ocasião da colheita foram avaliadas as seguintes características: estatura de planta (EP) em centímetros, altura de inserção do primeiro legume (IPL) em centímetros, diâmetro do colo (DC) em milímetros, número de legumes por planta (NLP) e número de grãos por legume (NGL) de acordo com o International plant genetic resources institute (2001).

Para análise dialélica foi utilizada a metodologia proposta por Griffing (1956), método I, onde são incluídas n2 combinações, através do seguinte modelo estatístico (Equação 1): 
$Y_{i j}=m+g_{i}+g_{j}+s_{i j}+\varepsilon_{i j}$

em que $Y_{i:}$ : valor médio da combinação híbrida $(i \# j)$ ou do genitor $(i=j), m$ : média geral, $g_{i}$ e $g_{j}$ : efeitos da capacidade geral de combinação do $i$-ésimo e do $j$-ésimo genitor, respectivamente; $s_{i j}$ : efeito da capacidade específica de combinação para os cruzamentos entre os genitores de ordem $i$ e $j, \varepsilon_{i j}$ : erro experimental.

As análises foram realizadas com o auxílio do programa computacional SAS 9.1.3 por meio do macro DIALLEL-SAS05, descrito por Zhang, Kang e Lankey (2005). Os efeitos genéticos aditivos envolvidos na determinação dos caracteres foram calculados pela relação entre os quadrados médios da capacidade geral de combinação $(C G C)$ e capacidade específica de combinação $(C E C)$, em cada caráter estudado (Equação 2):

$\% C G C=\frac{C G C}{C G C+C E C} X 100$

\section{RESULTADOS E DISCUSSÃO}

Houve significância a 5\% de probabilidade de erro, pelo teste $\mathrm{F}$, na análise de variância, para os quadrados médios de tratamento (QM), em todos os caracteres avaliados, com exceção do número de legumes por planta (Tabela 1). As significâncias verificadas para a grande maioria das características indicam a existência de variabilidade, resultante da ação de efeitos gênicos aditivos e não aditivos, denotando a possibilidade de obtenção de novas cultivares (SILVA et al., 2004).

As somas de quadrados de tratamentos foram desdobradas em capacidade geral de combinação (CGC) e capacidade específica de combinação (CEC). O efeito da capacidade geral (CGC) revelou significância para os caracteres EP, IPL, DC e NGL, indicando que para estas características, existe pelo menos um genitor superior aos demais, com relação ao seu desempenho médio em combinações híbridas (RODRIGUES; LEAL; PEREIRA, 1998). A presença de significância para a CGC reflete a elevada importância dos efeitos gênicos aditivos na expressão dos caracteres avaliados, para o conjunto de genótipos testados (PÁDUA et al., 2010). Na cultura do feijão são utilizadas apenas linhas puras ou suas misturas, dessa forma a seleção é praticada geralmente em gerações mais avançadas onde maior progresso pode ser obtido. Nessas gerações, o sucesso da seleção depende da diversidade genética devida ao efeito aditivo dos genes, e é por esta razão que o conhecimento da CGC dos genitores é de grande valia para os melhoristas de feijão (RAMALHO; SANTOS; ZIMMERMANN, 1993).

Já a CEC mostrou efeito significativo para o caráter diâmetro do colo. A significância dos quadrados médio relativo à $\mathrm{CEC}$ indica que efeitos gênicos não aditivos estão

Tabela 1 - Análise dialélica para os caracteres: estatura de plantas em cm (EP), altura de inserção do primeiro legume em cm (IPL), diâmetro do colo em mm (DC), número de legumes por planta (NLP) e número de grãos por legume (NGL), com os respectivos graus de liberdade (GL) e quadrados médio (QM) de cada efeito: capacidade geral de combinação (CGC), capacidade específica de combinação (CEC), efeito recíproco (REC), efeito materno (MAT) e efeito não-materno (NMAT), avaliados por meio de um dialelo completo envolvendo quatro genitores em feijão

\begin{tabular}{lccrrrrrrrr}
\hline \multirow{2}{*}{ F.V. } & \multicolumn{3}{c}{ EP } & \multicolumn{2}{c}{ IPL } & \multicolumn{2}{c}{ DC } & \multicolumn{2}{c}{ NLP } & \multicolumn{2}{c}{ NGL } \\
\cline { 2 - 11 } & GL & \multicolumn{1}{c}{ QM } & GL & QM & GL & QM & GL & QM & GL & QM \\
\hline Tratamento & 15 & $3850,18^{*}$ & 15 & $50,12^{*}$ & 15 & $7,30^{*}$ & 15 & 41,60 & 15 & $2,98^{*}$ \\
CGC & 3 & $17194,15^{*}$ & 3 & $113,61^{*}$ & 3 & $24,98^{*}$ & 3 & 85,60 & 3 & $5,80^{*}$ \\
CEC & 6 & 575,34 & 6 & 23,60 & 6 & $5,82^{*}$ & 6 & 56,10 & 6 & 1,36 \\
REC & 6 & 461,00 & 6 & $45,08^{*}$ & 6 & 1,12 & 6 & 20,10 & 6 & $3,06^{*}$ \\
MAT & 3 & $834,73^{*}$ & 3 & 61,94 & 3 & 1,10 & 3 & 20,60 & 3 & $2,70^{*}$ \\
NMAT & 3 & 97,89 & 3 & 29,46 & 3 & 1,13 & 3 & 19,80 & 3 & $3,46^{*}$ \\
Resíduo & 318 & 295,31 & 318 & 14,11 & 316 & 1,61 & 317 & 45,30 & 315 & 0,99 \\
Total & 356 & & 356 & & 354 & & 355 & & 353 & \\
\hline R & & 0,39 & & 0,18 & & 0,22 & & 0,11 & & 0,16 \\
C.V. $(\%)$ & & 30,22 & & 26,02 & & 28,08 & & 51,84 & & 23,40 \\
CGC (\%) & & 96,76 & & 82,80 & & 81,10 & & 60,41 & & 81,00 \\
\hline
\end{tabular}

*Significativo a $5 \%$ de probabilidade pelo teste $\mathrm{F}$ 
envolvidos no controle dessa característica (SIBIYA et al., 2011) e que as combinações híbridas obtidas diferem entre si.

As características IPL e NGL apresentaram efeito recíproco significativo. A significância REC apresenta implicações na estimativa dos efeitos genéticos. Este efeito pode ser divido ainda em efeito materno (MAT) e nãomaterno (NMAT) (WU; MATHESON, 2001). Os efeitos maternos são atribuíveis a fatores genéticos citoplasmáticos, e os efeitos não maternos podem ser explicados pelainteração entre genes nucleares e efeitos de genes citoplasmáticos (MUKANGA; DERERA; TONGOONA, 2010).

Quando o efeito do recíproco é devido ao componente materno, este pode persistir durante as gerações e pode ser explorado, porém, se for devido ao componente não-materno o efeito pode ser perdido durante as gerações. Por isso, como estratégia de melhoramento, há necessidade de considerar os fatores nucleares e não nucleares na seleção de plantas, pois quando há efeito recíproco é fundamental a definição de qual genitor será utilizado como fêmea ou macho (WU; MATHESON, 2001). Logo, na seleção de plantas para EP e NGL deve ser considerada a possibilidade da presença de efeitos citoplasmáticos, já que o efeito materno se mostrou significativo. Efeitos citoplasmáticos tem inequívoca relevância para os caracteres que conferem qualidade nutricional e tecnológica ao feijão, pois terão implicações diretas na seleção e na condução das populações segregantes em programas de melhoramento (LONDERO et al., 2009).

Para NLP nenhum efeito avaliado se mostrou significativo, o que pode ser um indicativo da dissimilaridade restrita entre os genitores para esta característica, onde a similaridade entre os genitores não propiciou uma variação de magnitude tal que permitisse a detecção de diferenças significativas (JUNG et al., 2007).

A variância genética aditiva foi o componente mais relevante para todos os caracteres avaliados, já que os efeitos de CGC foram maiores que os efeitos da CEC (SIBIYA et al., 2011). A participação relativa da CGC foi de 96,$76 ; 82,80 ; 81,10 ; 60,41$ e $81,00 \%$ para os caracteres EP, IPL, DC, NLP e NGL, respectivamente (Tabela 1). Esta é uma manifestação clara da predominância dos efeitos genéticos aditivos no controle destas características. Isso implica que a seleção artificial de plantas com as características desejáveis dará progênies também com desempenho superior (THANH et al., 2010), pois quando estão presentes efeitos aditivos dos genes a média dos pais é igual à média da $\mathrm{F}_{1}, \mathrm{~F}_{2}$ e assim consecutivamente (RAMALHO; SANTOS; PINTO, 2008). Sendo, que dentre os métodos de melhoramento, o Pedigree, pode ser considerado o método de condução de população segregante mais eficiente (KIMANI et al., 2007).
A escolha dos genitores para formação das populações segregantes é crucial para obtenção de êxito nos programas de melhoramento, sendo a capacidade combinatória, com presença de genes complementares, a grande responsável pelo sucesso (LORENCETTI et $a l .$, 2005). A seleção de parentais com base na avaliação fenotípica é insuficiente para assegurar a obtenção de progênies com elevada frequência de segregantes transgressivos (JUNG et al., 2007). Assim, a escolha de parentais deve ser fundamentada na informação genética como um todo e no conhecimento do potencial da capacidade combinatória dos parentais em nível expressivo para produzirem, em alta frequência, recombinações favoráveis (AHMED; HAKIM;ZARGAR, 1998; ALLARD, 1999). Considera-se ainda que o efeito de CGC é um indicador da superioridade do parental e de sua divergência relativa entre os demais parentais.

Assim, de acordo com a estimativa dos efeitos da CGC, a qual determina o desempenho médio de cada genitor em uma série de cruzamentos e é uma estimativa do valor genético (TORRES; GERALDI, 2007), pode-se indicar a utilização do genótipo BAF09 quando o foco do programa de melhoramento for obter populações segregantes e linhas puras com valores menores para as características EP (-9,68 cm), IPL (-0,84 cm), DC (-0,58 mm) e NGL $(-0,26)$. Bem como, o genótipo BAF50, que mostra comportamento similar quanto a $\mathrm{EP}$, sendo que este genitor quando usado em cruzamentos tende a diminuir em $3,72 \mathrm{~cm}$ a estatura de planta. Por outro lado, o caráter DC pode ser aumentado em 0,33 $\mathrm{mm}$ (Tabela 2).

Porém, o ideótipo de feijão que pode ser utilizado como alternativa para cultivo no Planalto Catarinense é aquele que combine além das características estatura e inserção do primeiro legume elevadas, maior diâmetro do colo e maior rendimento de grãos, comuns entre os

Tabela 2 - Estimativa da capacidade geral de combinação ( $\hat{g} i)$ para os caracteres estatura de plantas em cm (EP), altura de inserção do primeiro legume em cm (IPL), diâmetro do colo em mm (DC), número de legumes por planta (NLP) e número de grãos por legume (NGL), envolvendo quatro genitores utilizados em cruzamento dialélico de feijão

\begin{tabular}{lccccc}
\hline \multirow{2}{*}{ Genitores } & \multicolumn{5}{c}{$\hat{g} i$} \\
\cline { 2 - 6 } & EP & IPL & DC & NLP & NGL \\
\hline BAF09 & $-9,68^{*}$ & $-0,84^{*}$ & $-0,51^{*}$ & $-0,58$ & $-0,24^{*}$ \\
BAF07 & $13,13^{*}$ & $0,99^{*}$ & $0,17^{*}$ & 0,82 & $0,17^{*}$ \\
BAF50 & $-3,72^{*}$ & $-0,34$ & $0,33^{*}$ & $-0,54$ & 0,07 \\
IPR Uirapuru & 0,27 & 0,18 & 0,01 & 0,30 & 0,01 \\
\hline
\end{tabular}

*Significativo a $5 \%$ de probabilidade pelo teste $\mathrm{t}$ 
programas de melhoramento de feijão, o ciclo tardio, já que apenas uma colheita anual é possível sob as condições locais do clima e solo (BERTOLDO et al., 2009). Logo, os genótipos BAF09 e BAF50 não atendem estes objetivos. Já BAF07 é o genitor com maior potencial genético em transferir alelos favoráveis, visando melhorar o desempenho das populações, pois pode incrementar favoravelmente $13,13 \mathrm{~cm}$ em EP, 0,99 cm em IPL, 0,17 mm para DC, e 0,17 para NGL (Tabela 2). Ou seja, este genótipo agrega ao ideótipo de planta e ao rendimento de grãos, já que o número de grãos por legume é um dos componentes primordiais. Eainda, de acordo com Miranda, Costa e Cruz (1988), os genitores que apresentarem as mais elevadas CGC devem ser preferidos para constituírem os blocos de cruzamentos, favorecendo a seleção de linhagens homozigotas em espécies autógamas.

Os efeitos CEC ( $\mathrm{Sij}$ ) podem ser interpretados como o desvio de um híbrido em relação ao que seria esperado com base nas capacidades gerais de combinação de seus genitores (GOMES et al., 2000). Os maiores valores sãopara os genótipos mais dissimilares nas frequências dos genes com dominância, embora sejam também influenciados pela frequência gênica média do dialelo. Foram observados efeitos significativos da CEC apenas para as caraterísticas IPL, no cruzamento BAF09 x IPR Uirapuru $(0,91)$ e para DC nos cruzamentos BAF07 x BAF50 e BAF50 x IPR
Uirapuru (0,41 e 0,31, respectivamente) (Tabela 3). Os efeitos significativos e positivos da CEC indicam que estas combinações híbridas apresentam incremento no valor dos caracteres o que não pode ser explicado pela média dos pais e suas capacidades gerais de combinação (KOSTETZER; MOREIRA; FERREIRA, 2009).

Os efeitos da capacidade específica de combinação, apesar de serem úteis na indicação das melhores combinações híbridas, não evidenciam se o comportamento dos híbridos pode ser alterado com a utilização de genitores ora como fêmea ou como macho. Para fazer tal inferência, são utilizadas estimativas dos efeitos recíprocos (rij) (GOMES et al., 2000). Assim, quando BAF07 é usado como fêmea e BAF09 como macho uma redução na EP em $6,79 \mathrm{~cm}$ pode ser observada. Por outro lado se o genótipo BAF07 for utilizado como genitor masculino em cruzamentos com BAF50 e IPR Uirapuru um acréscimo para IPL pode ser obtido. Quando o genitor IPR Uirapuru foi empregado como fêmea no cruzamento com BAF 50 uma decréscimo de aproximadamente $1 \mathrm{~cm}$ na EP pode ser notado. Para NGL os cruzamentos BAF07 x BAF09 e IPR Uirapuru x BAF07 são os mais promissores, pois agregam em média 0,4 grãos por legume (Tabela 3).

É importante ressaltar que nem sempre dois genitores de alta capacidade geral, quando cruzados,

Tabela 3 - Estimativa da capacidade específica de combinação $\left(\hat{S}_{i j}\right)$ e efeito dos recíprocos $\left(r_{i j}\right)$ para os caracteres estatura de plantas em cm (EP), altura de inserção do primeiro legume em cm (IPL), diâmetro do colo em mm (DC), número de legumes por planta (NLP) e número de grãos por legume (NGL), envolvendo para as 12 combinações possíveis nos cruzamentos dialélicos entre quatro genótipos de feijão

\begin{tabular}{lcccccc}
\hline & Genitor & & & & $S_{i j}$ & \\
\hline I & J & EP & IPL & DC & NLP & NGL \\
1 & 2 & $-0,82$ & $-0,38$ & $-0,08$ & 0,07 & $-0,23$ \\
1 & 3 & 0,49 & $-0,21$ & 0,14 & 0,93 & $-0,03$ \\
1 & 4 & $-3,80$ & $0,91^{*}$ & $-0,23$ & $-0,08$ & 0,20 \\
2 & 3 & 3,85 & $-0,47$ & $0,41 *$ & 0,19 & $-0,07$ \\
2 & 4 & $-0,89$ & $-0,52$ & $-0,06$ & 1,17 & 0,01 \\
3 & 4 & 2,68 & 0,51 & $0,31 *$ & 0,70 & $-0,08$ \\
\hline & Genitor & & & $r_{i j}$ & NLP & NGL \\
1 & I & EP & IPL & DC & $-0,03$ & $0,36 *$ \\
1 & 2 & $-6,79 *$ & $-0,30$ & 0,02 & 0,58 & $-0,28^{*}$ \\
1 & 3 & $-1,45$ & $-0,28$ & $-0,22$ & $-0,46$ & $-0,13$ \\
2 & 4 & $-2,34$ & $-0,90$ & $-0,06$ & 0,54 & $-0,12$ \\
2 & 3 & 1,43 & $1,30^{*}$ & 0,19 & 1,29 & $0,31^{*}$ \\
3 & 4 & 2,30 & $1,51^{*}$ & 0,13 & 0,55 & 0,29 \\
\hline
\end{tabular}

* Significativo a 5\% de probabilidade pelo teste t, $(* /) 1$ - BAF09; 2 - BAF07; 3 - BAF50; 4 - IPR Uirapuru 
originam o melhor híbrido do dialelo (CRUZ; VENCOVSKY, 1989). De acordo com Griffing (1956), a melhor combinação híbrida é aquela com maior CEC (Sij ou rij) dos genitores, cujos parentais apresentem alta CGC. As combinações híbridas que podem ser destacadas são aquelas que possuem BAF07 no cruzamento: para DC a combinação BAF07 x BAF50 acrescenta 0,41 mm; para IPL as combinações BAF50 x BAF07 e IPR Uirapuru $x$ BAF07 acrescentam 1,30 e 1,51 cm, respectivamente. Esta ultima combinação além de agregar valores à altura de inserção do primeiro legume atua positivamente no aumento do NGL $(0,31)$.

O genótipo BAF07 apresentou desempenho superior para todas as características avaliadas, com exceção para DC e NLP (Tabela 4). Em geral, os dados da CGC são associados às médias, ou seja, maiores médias também apresentam valores altos de CGC. Novamente nenhum efeito diferencial foi constatado para a caraterística NLP, mostrando que tanto os genitores empregados, como os híbridos obtidos são muito semelhantes.

O número de contrastes significativos entre híbridos vs genitores foi pequeno (apenas 20\%). Porém, quando os genitores são confrontados é possível observar significância para a maioria das comparações. Esta estimativa é muito importante, pois para que os resultados de uma análise dialélica sejam coerentes, é necessário que os genitores hibridados sejam contrastantes. Por estes resultados (Tabela 5) fica evidente, ainda, a importância da avaliação do efeito recíproco, já que em algumas combinações o híbrido $F_{1}$ diferiu da média dos genitores (BAF09 x BAF50, para EP, por exemplo), porém, o recíproco não (BAF50 x BAF09).

A comparação entre a média dos genitores e os híbridos em cada combinação mostrou a inexistência de direção predominante para o efeito da heterose. Para EP apenas os contrastes BAF09 x BAF50 vs genitores e BAF07 x IPR Uirapuru vs genitores apresentaram significância. Para o primeiro contraste uma redução de $9 \mathrm{~cm}$ na estatura foi observada, por outro lado, para o segundo contraste a geração $F_{1}$ apresentou um desempenho superior de $10 \mathrm{~cm}$ aproximadamente em relação à média dos genitores.

Da mesma forma, para IPL pode ser observada heterose tanto negativa quanto positiva. BAF50 x BAF09 e BAF50 x IPR Uirapuru mostraram valores maiores que a média dos genitores, por outro lado BAF50 x BAF07 e IPR Uirapuru x BAF07 apresentaram valores menores do que a média dos genitores. Quando a variável de interesse estudada foi o DC em mm pode-se observar a superioridade dos híbridos em relação à média dos genitores para todas as combinações significativas: BAF07 x IPR Uirapuru, IPR Uirapuru x BAF09, IPR

Tabela 4 - Médias dos caracteres estatura de planta (EP), inserção do primeiro legume (IPL), diâmetro do colo (DC), número de legumes por planta (NLP) e número de grãos por legume (NGL) dos parentais e híbridos simples em feijão

\begin{tabular}{|c|c|c|c|c|c|}
\hline Genótipos & $\mathrm{EP}(\mathrm{cm})$ & $\mathrm{IPL}(\mathrm{cm})$ & $\mathrm{DC}(\mathrm{mm})$ & NLP & NGL \\
\hline BAF09 x BAF07 & 52,75 cde & $13,95 \mathrm{bc}$ & $4,12 \mathrm{bcd}$ & $13,31 \mathrm{a}$ & $4,28 \mathrm{abc}$ \\
\hline BAF09 x BAF50 & $41,36 \mathrm{e}$ & $13,82 \mathrm{bc}$ & $3,74 \mathrm{~d}$ & $12,27 \mathrm{a}$ & $4,05 \mathrm{abc}$ \\
\hline BAF09 x IPR Uirapuru & $42,54 \mathrm{de}$ & $12,79 \mathrm{bc}$ & $4,27 \mathrm{bcd}$ & $13,41 \mathrm{a}$ & $3,73 \mathrm{bc}$ \\
\hline BAF07 x BAF09 & $66,33 \mathrm{abc}$ & $14,54 \mathrm{abc}$ & $4,08 \mathrm{~cd}$ & $13,37 \mathrm{a}$ & $3,56 \mathrm{c}$ \\
\hline BAF07 x BAF50 & $71,73 \mathrm{ab}$ & $16,63 \mathrm{abc}$ & 4,78 abcd & $16,63 \mathrm{a}$ & $4,73 \mathrm{ab}$ \\
\hline BAF07 x IPR Uirapuru & $71,61 \mathrm{ab}$ & $15,96 \mathrm{bc}$ & $5,63 \mathrm{a}$ & $14,04 \mathrm{a}$ & $4,27 \mathrm{abc}$ \\
\hline BAF50 x BAF09 & 46,04 de & $15,61 \mathrm{abc}$ & $3,85 \mathrm{~d}$ & $13,14 \mathrm{a}$ & $4,31 \mathrm{abc}$ \\
\hline BAF50 x BAF07 & $67,13 a b c$ & $13,60 \mathrm{bc}$ & 4,52 abcd & $14,04 \mathrm{a}$ & $4,09 \mathrm{abc}$ \\
\hline BAF50 x IPR Uirapuru & 57,71 bcde & $15,95 \mathrm{abc}$ & 4,79 abcd & $12,95 \mathrm{a}$ & $3,91 \mathrm{abc}$ \\
\hline IPR Uirapuru x BAF09 & 45,43 de & $13,34 \mathrm{bc}$ & $4,71 \mathrm{abcd}$ & $12,26 \mathrm{a}$ & $4,30 \mathrm{abc}$ \\
\hline IPR Uirapuru x BAF07 & $68,73 \mathrm{abc}$ & $13,34 \mathrm{bc}$ & $5,26 \mathrm{abc}$ & $12,95 \mathrm{a}$ & $4,52 \mathrm{abc}$ \\
\hline IPR Uirapuru x BAF50 & 54,57 bcde & $13,66 \mathrm{bc}$ & $5,40 \mathrm{ab}$ & $14,04 \mathrm{a}$ & $4,50 \mathrm{abc}$ \\
\hline BAF09 & $41,66 \mathrm{e}$ & $12,45 \mathrm{c}$ & $3,66 \mathrm{~d}$ & $10,95 \mathrm{a}$ & $3,80 \mathrm{bc}$ \\
\hline BAF07 & $81,04 \mathrm{a}$ & $17,83 \mathrm{a}$ & 4,60 abcd & $13,25 \mathrm{a}$ & $4,86 \mathrm{a}$ \\
\hline BAF50 & $59,47 \mathrm{bcd}$ & $13,92 \mathrm{bc}$ & $4,52 \mathrm{abcd}$ & $11,85 \mathrm{a}$ & $4,08 \mathrm{abc}$ \\
\hline IPR Uirapuru & $42,58 \mathrm{de}$ & $13,95 \mathrm{bc}$ & $4,35 \mathrm{abcd}$ & $10,12 \mathrm{a}$ & $4,57 \mathrm{abc}$ \\
\hline
\end{tabular}


Tabela 5 - Estimativa de contratares de médias entre $\mathrm{F}_{1}$ e recíprocos $v s$ a média dos genitores, e dos genitores $v s$ genitores de feijão para os caracteres estatura de planta $(\mathrm{EP} \mathrm{em} \mathrm{cm})$, inserção do primeiro legume (IPL em $\mathrm{cm}$ ), diâmetro do colo (DC em mm), número de legumes por planta (NLP) e número de grãos por legume (NGL)

\begin{tabular}{lcrrrr}
\hline \multirow{2}{*}{ Contraste } & \multicolumn{5}{c}{ Quadrado Médio } \\
\cline { 2 - 6 } & \multicolumn{1}{c}{ EP } & IPL & DC & NLP & NGL \\
\hline BAF09 x BAF07 vs genitores & 1045,15 & 20,19 & 0,00 & 19,98 & 0,04 \\
BAF09 x BAF50 vs genitores & $1250,93^{*}$ & 5,76 & 1,82 & 9,91 & 0,17 \\
BAF09 x IPR Uirapuru $v s$ genitores & 3,67 & 2,78 & 1,09 & 132,25 & 3,31 \\
BAF07 x BAF09 vs genitores & 396,67 & 5,84 & 0,04 & 25,84 & $9,28^{*}$ \\
BAF07 x BAF50 vs genitores & 29,14 & 7,52 & 0,68 & $221,87^{*}$ & 0,89 \\
BAF07 x IPR Uirapuru $v s$ genitores & $1511,29^{*}$ & 0,06 & $20,20^{*}$ & 86,31 & 3,06 \\
BAF50 x BAF09 vs genitores & 292,6 & $84,12^{*}$ & 0,81 & 43,05 & 1,93 \\
BAF50 x BAF07 vs genitores & 148,74 & $78,46^{*}$ & 0,03 & 33,74 & 2,21 \\
BAF50 x IPR Uirapuru $v s$ genitores & 650,87 & $57,70^{*}$ & 4,13 & 55,00 & 2,46 \\
IPR Uirapuru x BAF09 vs genitores & 176,83 & 0,30 & $7,77^{*}$ & 45,96 & 0,20 \\
IPR Uirapuru x BAF07 $v s$ genitores & 759,55 & $100,95^{*}$ & $9,50^{*}$ & 25,04 & 0,63 \\
IPR Uirapuru x BAF50 $v s$ genitores & 185,72 & 1,10 & $13,33^{*}$ & 133,58 & 0,40 \\
BAF09 $v$ BAF07 & $18604,68^{*}$ & $346,68^{*}$ & $10,54^{*}$ & 63,02 & $13,41^{*}$ \\
BAF09 $v$ BAF50 & $3552,40^{*}$ & 24,21 & $8,22^{*}$ & 9,05 & 0,88 \\
BAF09 $v$ IPR Uirapuru & 7,52 & 27,00 & $5,67^{*}$ & 8,33 & $7,13^{*}$ \\
BAF07 vs BAF50 & $5208,78^{*}$ & $170,76^{*}$ & 0,07 & 21,73 & $6,77^{*}$ \\
BAF07 vs IPR Uirapuru & $17864,08^{*}$ & $180,18^{*}$ & 0,75 & 117,19 & 0,99 \\
BAF50 $v$ IPR Uirapuru & $3243,60^{*}$ & 0,01 & 0,32 & 33,60 & 2,70 \\
\hline
\end{tabular}

*Significativo a $5 \%$ de probabilidade pelo teste $\mathrm{F}$

Uirapuru x BAF07 e IPR Uirapuru x BAF50. Para o componente do rendimento NLP a combinação entre os genótipos BAF07 e BAF50 proporcionou um incremento de aproximadamente 4 legumes por planta. Já BAF07 quando hibridado com BAF09 resultou uma redução para NGL de aproximadamente uma unidade (Tabela 5).

\section{CONCLUSÕES}

1. O genótipo BAF07 pode ser indicado para uso em blocos de cruzamentos quando o escopo do programa for aumentar os valores para EP, IPL, DC e NGL; em contrapartida o genótipo BAF09 não deve ser empregado, já que atua reduzindo os valores para todas estas características;

2. Existe predomínio da variância aditiva no controle genético em genótipos de feijão;

3. O efeito recíproco foi importante principalmente para as caraterísticas EP, IPL e NGL.

\section{AGRADECIMENTOS}

À UDESC, ao CNPq, à CAPES e à FAPESC pela concessão de bolsa de estudo e pelo apoio financeiro no desenvolvimento deste trabalho.

\section{REFERÊNCIAS}

AHMED, N.; HAKIM, M. A.; ZARGAR, G. H. Combining ability studies in okra (Abelmoschus esculentus (L.) Moench). Vegetable Science, v. 24, n. 2, p. 95-98, 1997.

ALGHAMDI, S. Genetic behavior of some selected faba bean genotypes. African Crop Science Proceedings, v. 8, p. 709-714, 2007.

ALLARD, R. W. Principles of plant breeding. New York: John Wiley, 1999. $485 \mathrm{p}$.

BERTOLDO, J. B. et al. Genetic gain in agronomic traits of common bean in the region of Planalto Catarinense. Euphytica, v. 117, n. 3, p. 381-388, 2009. 
CARVAJAL, C. Q. et al. Seleção para período de florescimento e estatura de planta e seu efeito no rendimento de grãos de trigo. Pesquisa Agropecuária Brasileira, v. 32, n. 11, p. 1176-1176, 1997.

CRUZ, C. D.; REGAZZI, A. J. Modelos biométricos aplicados ao melhoramento genético.Viçosa: Imprensa Universitária, 2004. 480 p.

CRUZ, C. D.; VENCOVSKY, R. Comparação de alguns métodos de análise dialélica. Revista Brasileira de Genética, v. 12 , n. 2 , p. $425-438,1989$.

FERREIRA, J. M.; MOREIRA, R. M. P.; HIDALGO, J. A. F. Capacidade combinatória e heterose em populações de milho crioulo. Ciência Rural, v. 39, n. 2, p. 332-339, 2009.

GOMES, M. S. et al. Estimativas da capacidade de combinação de linhagens de milho tropical para qualidade fisiológica. Ciência Agrotécnica, v. 24, p. 41-49, 2000. Edição Especial.

GRIFFING, B. Concept of general and specific combining ability in relation to diallel crossing systems. Australian Journal of Biological Sciences, v. 9, p. 463-493, 1956.

INTERNATIONAL PLANT GENETIC RESOURCES INSTITUTE. Descritores para Phaseolus vulgaris $\boldsymbol{L}$. Rome: International Plant Genetic Resources Institute, 2001. 45 p.

JUNG, M. S. et al. Capacidade geral e específica de combinação de caracteres do fruto do maracujazeiro doce (Passiflora alata Curtis). Ciencia Rural, v. 37, n. 4, p. 963-969, 2007.

KIMANI, J. M. et al. Mode of inheritance of common bean (Phaseolus vulgaris L.) traits for tolerance to low soil phosphorus (P). Euphytica, v. 155, n. 1/2, p. 225-234, 2007.

KOSTETZER, V.; MOREIRA, R. M. P.; FERREIRA, J. M. Cruzamento dialélico parcial entre variedades locais do Paraná e variedades sintéticas de milho. Pesquisa Agropecuária Brasileira, v. 44, n. 9, p. 1152-1159, 2009.

LONDERO, P. M. G. et al. Efeito materno na expressão dos teores de aminoácidos sulfurados em grãos de feijão. Ciência Rural, v. 39, n. 6, p. 1884-1887, 2009.

LORENCETTI, C. et al. Capacidade combinatória e heterose em cruzamento dialélico de aveia (Avena sativa 1.) Revista Brasileira Agrociência, v. 11, n. 2, p. 143-148, 2005.

MIKLAS, P. N. et al. Common bean breeding for resistance against biotic and abiotic stresses: from classical to MAS breeding. Euphytica, v. 147, n. 1/2, p. 105-131, 2006.

MIRANDA, J. E. C.; COSTA, C. P.; CRUZ, C. D. Análise dialélica em pimentão. I. Capacidade combinatória. Revista Brasileira de Genética, v. 11, n. 2, p. 431-440, 1988.

MUKANGA, M.; DERERA, J.; TONGOONA, P. Gene action and reciprocal effects for ear rot resistance in crosses derived from five tropical maize populations. Euphytica, v. 174, n. 2, p. 293-301, 2010.
NASCIMENTO, I. R. et al. Capacidade combinatória e ação gênica na expressão de caracteres de importância econômica em pimentão. Ciência Agrotécnica, v. 28, n. 2, p. 251-260, 2004.

NASS, H. G. Selecting superior spring wheat crosses in early generations. Euphytica, v. 28, n. 1, p. 161-167, 1979.

PÁDUA, T. R. P. et al. Capacidade combinatória de híbridos de tomateiro de crescimento determinado, resistentes a Begomovirus e Tospovirus. Pesquisa Agropecuária Brasileira, v. 45 , n. 8 , p. $818-825,2010$.

PEREIRA, H. S. et al. Informações fenotípicas e marcadores microssatélites de QTL na escolha de populações segregantes de feijoeiro. Pesquisa Agropecuária Brasileira, v. 42, n. 5, p. 707-713, 2007.

RAMALHO, M. A. P.; SANTOS, J. B.; ZIMMERMANN, M. J. O. Genética quantitativa em plantas autógamas: aplicações ao melhoramento do feijoeiro. Goiânia: UFG, 1993. 271 p.

RAMAlHO, M. A. P.; SANTOS, J. B.; PINTO, C. A. B. P. Genética na Agropecuária. 4. ed. Lavras: UFLA, 2008. 464 p.

REDE OFICIAL DE LABORATÓRIOS DE ANÁLISE DE SOLO E DE TECIDO VEGETAL. Manual de adubação e calagem para os estados do Rio Grande do Sul e Santa Catarina. 10. ed. Porto Alegre: Sociedade Brasileira de Ciência do Solo, 2004. 400 p.

RODRIGUES, R.; LEAL, N. R.; PEREIRA, M. G. Análise dialélica de seis características agronômicas em Phaseolus vulgaris L. Bragantia, v. 57, n. 2, p. 241-250, 1998.

SIBIYA, J. et al. Combining ability analysis for Phaeosphaeria leaf spot resistance and grain yield in tropical advanced maize inbred lines. Field Crops Research, v. 120, n. 1, p. 86-93, 2011.

SILVA, M. P. et al. Análise dialélica da capacidade combinatória em feijão-de-vagem. Horticultura Brasileira, v. 22 , n. 2 , p. $277-280,2004$.

THANH, M. N. et al. Estimates of strain additive and nonadditive genetic effects for growth traits in a diallel cross of three strains of giant freshwater prawn (Macrobrachium rosenbergii) in Vietnam. Aquaculture, v. 299, n. 1/4, p. 30-36, 2010.

TORRES, E. A.; GERALDI, I. O. Partial diallel analysis of agronomic characters in rice (Oryza sativa L.). Genetics and Molecular Biology, v. 30, n. 3, p. 605-613, 2007.

VALÉRIO, I. P. et al. Combining ability of wheat genotypes in two models of diallel analyses. Crop Breeding and Applied Biotechnology, v. 9, n. 2, p. 100-107, 2009.

VIEIRA, C. O feijoeiro comum: cultura, doenças e melhoramento. Viçosa: UFV, 1967. 220 p.

WU, H. X.; MATHESON, A. C. Reciprocal, maternal and nonmaternal effects in radiata pine diallel mating experiment on four Australia sites. Forest genetics, v. 8, n. 3, p. 205-212, 2001.

ZHANG, Y.; KANG, M. S.; LANKEY, K. R. DIALLELSAS05: A comprehensive program for Griffing's and Gardner-Eberhart Analyses. Agronomy Journal, v. 97, n. 4, p. 1097-1106, 2005. 